2015-03-19

\title{
Nursing Students' Experiences with High-Fidelity Simulation
}

\author{
Rana Halabi Najjar \\ Oregon Health \& Science University \\ Bret Lyman \\ Brigham Young University - Provo, bret-lyman@byu.edu \\ Nick Miehl \\ Oregon Health \& Science University
}

Follow this and additional works at: https://scholarsarchive.byu.edu/facpub

Part of the Other Nursing Commons

\section{Original Publication Citation}

Najjar, R. H., Lyman, B., \& Miehl, N. (2015). Nursing students' experiences with high-fidelity simulation. International Journal of Nursing Education Scholarship, 12(1).

\section{BYU ScholarsArchive Citation}

Najjar, Rana Halabi; Lyman, Bret; and Miehl, Nick, "Nursing Students' Experiences with High-Fidelity Simulation" (2015). Faculty Publications. 5064.

https://scholarsarchive.byu.edu/facpub/5064

This Peer-Reviewed Article is brought to you for free and open access by BYU ScholarsArchive. It has been accepted for inclusion in Faculty Publications by an authorized administrator of BYU ScholarsArchive. For more information, please contact ellen_amatangelo@byu.edu. 


\section{Nursing Students' Experiences with High-Fidelity Simulation}

\begin{abstract}
Research has revealed the effectiveness of simulation for facilitating student development of selfefficacy, knowledge, clinical judgment, and proficiency in technical skills. This grounded theory study was conducted to describe the experience of nursing students in high-fidelity simulation and develop a model which explicates the experience of nursing students in simulation. Focus group interviews were conducted with three cohorts of students enrolled in a baccalaureate nursing program who experienced simulation four to twelve times per academic year. Five prominent themes emerged during analysis Emotional Processing; Anxiety; Making Connections; Fidelity; and Learning. The Simulation Learning Model - Student Experience (SLM-SE) was developed to illustrate the student's multi-dimensional experience of learning through high-fidelity simulation. Findings from this study suggest that students are better equipped to learn through increasing confidence and experience, continued reflection-on action and enhanced peer-to-peer interaction. Recommendations for future research include developing strategies to optimize students' experiences for learning in simulation.
\end{abstract}

Keywords: nursing education, simulation, learning, grounded theory

DOI 10.1515/ijnes-2015-0010

\section{Background and purpose}

Nursing practice occurs in the context of a complex and dynamic healthcare environment. Within this environment, nurses are expected to fill roles that require them to practice at the full extent of their education

*Corresponding author: Rana Halabi Najjar, School of Nursing, Oregon Health \& Science University Monmouth Campus, 345N Monmouth Ave, Monmouth, OR 97361, USA, E-mail: najjar@ohsu.edu

Bret Lyman, College of Nursing, Brigham Young University, Provo, UT, USA, E-mail: bret-lyman@byu.edu

Nick Miehl, School of Nursing, Oregon Health \& Science University Monmouth Campus, 345N Monmouth Ave, Monmouth, OR 97361, USA, E-mail:miehl@ohsu.edu preparation (Institute of Medicine, 2011). Preparing nurses for success in these roles requires carefully designed educational experiences. Effective nursing education supports students in the development and integration of academic knowledge, clinical judgment, practical skills, and ethical comportment (Benner, Sutphen, Leonard, Day, \& Schulman, 2009).

A growing body of reliable evidence largely validates the effectiveness of simulation (Hayden, Smiley, Alexander, Kardong-Edgren, \& Jeffries, 2014) for facilitating student development of self-efficacy (Dunn, Osborne, \& Link, 2014), clinical knowledge (McCormick, de Slavy, \& Fuller, 2013), clinical judgment (Jensen, 2013; Lasater, 2007), and proficiency in technical skills (Aqel \& Ahmad, 2014). It is also well documented that students prefer simulation experiences over traditional teaching modalities (Cant \& Cooper, 2010).

Simulation researchers are beginning to explore specific elements of a simulation experience that influence its educational effectiveness. The National League for Nursing/Jeffries Simulation Framework (NLN/Jeffries Simulation Framework) is the most widely used framework for studying these specific elements. The NLN/Jeffries Simulation Framework depicts relationships between the design elements of the simulation, characteristics of the students and faculty, and characteristics of the educational practices used in simulation (Jeffries, 2005; Jones, Reese, \& Shelton, 2014). Despite these advances in simulation research, a potentially important element of the simulation experience has been overlooked in the NLN/Jeffries Simulation Framework and the research literature - the student's experience. Only one qualitative study of this nature was found in the literature. Cordeau (2012) collected written, qualitative data from 19 Junior-level nursing students about their first graded clinical simulation scenario.

Cordeau's (2012) data generated five themes. First, students have various levels of anxiety related to simulation. Second, students prepared for simulation by seeking information related to the scenario they were given, rehearsing the actions they intended to perform in the scenario, and envisioning themselves performing those actions. Third, students experienced the simulation scenario itself as an opportunity to perform nursing 
interventions in a realistic setting. Fourth, students learned and built confidence through the post-scenario process of debriefing and critiquing their performance. Fifth, students felt the overall simulation experience was helpful in preparing them for clinical practice.

Cordeau's (2012) work is an important first step toward describing the student experience of simulation. However, it has several limitations. Cordeau collected written, rather than verbal, responses, preventing the opportunity to ask clarifying questions or prompting additional depth in the responses. All of the participants were at the same point in their nursing program and were recruited from the same nursing class, potentially limiting the breadth of responses a more diverse sample may have generated. The participants had participated in simulation once, and experienced it as a graded activity. A more complete description of the student experience may be generated by participant groups with extensive simulation experience occurring over an extended period of time.

While important, Cordeau's study highlighted the critical gap in our understanding of student's experience and its potential impact on student learning. This study builds upon Cordeau's work by studying a larger, more diverse sample of students, all of whom have had many experiences with simulation over a time span of 1-3 years.

The purpose of this study was to examine the experiences of nursing students in high-fidelity simulation. Grounded theory was selected for this study because it provides a rigorous approach to conducting exploratory research (Glaser \& Strauss, 1967) and the development of new theory (Creswell, 2007). This study expanded the understanding of how students experience simulation, guiding nursing faculty to design more effective simulations. In addition, this study generated a new model for describing how students experience simulation, providing an initial framework for future qualitative and quantitative research. The new model may be complementary to the widely used NLN/Jeffries Simulation Framework.

The specific aims of this project were to (1) describe the experience of undergraduate nursing students in high-fidelity human patient simulation and (2) develop a model which explicates the experience of undergraduate nursing students in high-fidelity human patient simulation.

\section{Methods}

This qualitative, grounded theory, research design used focus group interviews to generate information regarding the experience of nursing students in simulation. This study was conducted in a baccalaureate nursing program in which nursing students experienced simulation between four and twelve times per academic year. One student cohort is admitted to the three-year program annually, so three student cohorts are enrolled in the program at any given time. Participants are students who are enrolled in the nursing program and are willing to take part in the study.

Using a relatively high number of informants (a total 26 students or over $25 \%$ of the students in the program) purposively sampled from students across multiple cohorts helped to maximize strength, create a representative sample (Miles \& Huberman, 1994), and ensure a broad range of simulation experiences. Conducting group interviews in a semi-structured conversational format served to control potential researcher bias (Bourdieu, 1990; Miles \& Huberman, 1994), while conducting these interviews offsite in a neutral social environment decreased the relative threat quotient (Miles \& Huberman, 1994).

In order to capture the essence of the student experience, three focus groups were interviewed by class (i.e. sophomores together, juniors together and seniors together). This provided a more comfortable context and allowed students to dialogue and delve deeper into their individual and shared experiences.

\section{Study procedure}

Approval to conduct this study was obtained through the Institutional Review Board. Focus groups consisted of 6-10 students, which allowed for active discussion while still providing opportunities for each participant to describe their own experience (Burns \& Grove, 2009). Participants were recruited by posting flyers on the campus where the nursing program is based. Focus group interviews occurred at a location apart from the School of Nursing building. At the beginning of each scheduled interview session, an information sheet describing the nature and purpose of the study, including risks and incentives, was distributed to the participants. Participants had the opportunity to withdraw from the study at that time; or at any point during the interview. No participants withdrew once the interviews had begun. No demographic data was collected from participants.

Two investigators were present during each focus group interview. One investigator asked questions and facilitated the focus group members' discussion. The other investigator was present to observe and digitally record the interview.

The following questions were used to initiate and guide the progression of the focus group interview. 
1. What it is like being in simulation?

2. What is it like getting ready for simulation?

3. What is debriefing like for you?

4. How do feel after simulation?

Focus group interviews were approximately 60-90 minutes in duration. Participants were given a $\$ 10$ gift certificate at the completion of the focus group interview.

\section{Data analysis}

All focus groups interviews were transcribed verbatim. Each investigator independently engaged in open coding, examining the data closely, word-by-word, for major categories, themes, and processes (Draucker, Martsolf, Ross, \& Rusk, 2007). The investigators then met to compare codes, discuss patterns, and themes which emerged from the transcripts. Connections between each of the themes identified through the coding process enabled the development of a substantive, coalesced framework which explicates the experience of undergraduate nursing students in high-fidelity human patient simulation.

Reliability was ensured by repeated reviewing of the data. All team members maintained a reflexive attitude toward the phenomenon of interest. According to Denzin (1978) triangulation techniques, including both data and investigator triangulation, are used to strengthen the rigor and credibility of qualitative research. Individual and collective analysis of the data from multiple interviews helped to increase the legitimacy and quality of conclusions. Data, categories, interpretation, and conclusions were confirmed with participants to ensure that reconstructions are adequate representations of their realities (Lincoln \& Guba, 1985; Sandelowski, 1993).

\section{Findings}

Five prominent themes emerged during analysis of the students' descriptions of their simulation experiences: Emotional Processing, Anxiety, Making Connections, Fidelity, and Learning. Each of these themes will be explored in more detail below.

\section{Emotional processing}

Emotional processing is defined as the active working through the emotions emerging as part of the simulation experience which included anxiety and fear. Students found it difficult to cognitively process what happened in the simulation until they had started processing it emotionally. For many, the first step in emotional processing was the dissipation of anxiety associated with the simulation, sometimes described as a "sigh of relief" that occurred immediately after the simulation ended. Some students began to emotionally process during debriefing and for others that process continued to occur for hours, days, or even weeks after the simulation.

For some students, being able to watch recordings of their simulation performance at a later time was helpful to their emotional processing. One student described "high anxiety" and being able to hear feedback during debriefing, but then being able to more fully process the feedback later with the video after “...everything [was] done." One student said "[reviewing the videos] I can see how I did things wrong and things I would like to change that I'm not aware of when I'm actually in sim".

Some students wanted their thoughts and feelings related to the simulation to be recognized and acknowledged by their peers. One student stated “...sometimes you come out feeling like you're the only one that felt that way or you were maybe frustrated [because] maybe [you weren't] prepared enough". Students were looking for validation from their peers during the debriefing, but were sometimes unable to experience it until later. In some situations, validation and emotional processing occurred days after the simulation experience, through informal debriefing sessions with classmates. A student commented on this experience by saying “....I think it was my birthday celebration where a group of us came together and so many of my classmates felt the same way". Students described this type of processing as debriefing about the experience of simulation itself and not necessarily the content within the scenario.

\section{Anxiety and fear}

Anxiety and fear were especially prominent themes and a nearly universal part of students' simulation experience. They used words such as "nerve wracking” and "overwhelmed" to describe how they felt, particularly during the scenario itself. One student expressed that most challenging part of simulation is working through the fear of being in simulation. However, students also recognized that anxiety is part of the process. It cannot be fully alleviated, and it can lead to learning. 
Several reasons were given for feelings of anxiety. These reasons included: feeling the need to "perform", lack of familiarity with simulation equipment, and unexpected developments during the simulation scenario.

Students recognized that they were being watched during simulation and expressed that "performing" in front of their peers created a lot of anxiety. One student summarized this sentiment well, saying, "I'm really anxious because I don't want to perform.” Anxiety also arose from feelings of inadequate performance during the simulation. One student said, “...you were told, 'these are the tasks you need to complete in simulation' and if you didn't complete them you came out feeling, well, I didn't do my job". Students' anxiety seemed to be stronger when larger peer-groups were watching. Feelings of simulation as a "performance" waned as students gained more experience in simulation and became more comfortable with the other students in their respective cohorts. Students began to feel more safe making mistakes during simulation, which decreased their anxiety. A student in the final year of the nursing program stated, "I think it's a safe place not to be perfect”.

Anxiety also arose from a lack of familiarity with the simulation equipment. Students with less experience in simulation were sometimes unsure of the manikin's capabilities. In addition, they did not know where to find needed supplies, or how to use equipment such as the patient monitor or the blood pressure device. This theme was less prominent with the students who had more experience in the simulation suite.

Students also felt anxiety when the simulation scenario unfolded differently than they had predicted during their preparation activities. Those with less experience in simulation tended to anticipate a fairly specific presentation and progression for the scenario, along with a set of specific, planned interventions. One student said, "One curve ball and I'm lost and reviewing it in my head." Students with more experience were able to prepare more generally for simulation, drawing on their clinical experience, past simulations, and their ability to work in teams to arrive ready to manage a broader range of possibilities within the scenario.

\section{Making connections}

During simulation, part of the student experience is making connections. Students try to link and reconcile their current simulation with previous healthcare, skills lab, simulation, and classroom experiences. Students attempt to "make connections" by connecting with other experiences, connecting with colleagues, and connecting with the future.

\section{Connecting with other experiences}

Students noticed and appreciated when classroom learning activities were closely linked to the important concepts and context of the simulation scenarios. If simulation scenarios were well aligned with the concepts and content from class, then students were able to make connections much more quickly.

Early in the nursing program, students with experience working in healthcare (e.g. Certified Nursing Assistants) tried to make connections between their healthcare and simulation experiences. When students identified discrepancies between their healthcare experience and the simulation experience, this sometimes became a substantive barrier to making connections with and learning from other aspects of the scenario. In fact, one student described that having no prior healthcare experience was beneficial for her. This released her from the task of trying to make similar connections as well as from the pressure of any personal expectations for how she should perform in simulation.

As students progressed through the program, they became more grounded in clinical and found it easier to incorporate clinical experiences and past simulation experiences into the current simulation. As a result, they felt less need to prepare as thoroughly for simulation. One student said:

I think that's just the natural evolution of the student nurse. The more time on the clock you have, the more you're going to be able to rapidly absorb information about a current situation that you're faced with in simulation

Students practiced certain skills in clinical and recognized they had practiced similar skills in simulation. Those who made this connection found the combination of simulation and clinical experiences to be helpful. Furthermore, simulation offered additional opportunities for supervision and feedback from faculty and peers compared to clinical.

\section{Connecting with colleagues}

Several factors influenced students' ability to make connections with each other, including time in the program, past interactions with peers, and simulation group sizes. First year students had more difficulty making connections 
with each other during simulation. As students experienced more simulation and more clinical time together, they were able to make connections and follow through with action much more quickly. Some students used a learning model that required them to work closely in collaborative dyads in the clinical setting. They felt this helped them connect with their partners in the simulation environment and work more cohesively during the scenario. They were more aware of each other's strengths and weaknesses and communicated more effectively during the simulation and in debriefing. Simulation group sizes affected students' ability to make connections with each other and subsequent mental and emotional processing. For example, students working in groups of eight were better able to relate to each other than students working in groups of 30 or more.

Another element of connecting with colleagues related to peer feedback. Initially giving feedback during debriefing was challenging to students:

At the beginning of the year it was really hard to give good feedback because we didn't want to hurt people's feelings.... and you're just getting to know each other and not super confident about your own ability to give good feedback.

However, as students became more familiar with each other, they were more comfortable providing constructive feedback. "I think the more we get to know each other we can give more balanced feedback." Some students wanted their peers to feel comfortable giving them honest feedback, even if not positive, to support continued learning. "...the feedback that you get from your classmates is only to help you and it's not to tear you down". Students recognized the experience of giving and receiving feedback would be "stressful" and "difficult" if their class was not cohesive.

One cohort of students discussed the benefits of debriefing in smaller groups of 8-10 students as opposed to larger groups of 30 or more. Constructive feedback was easier to provide when students were in smaller groups. Using the Lasater Clinical Judgment Rubric (Lasater, 2007) to focus the student's observation of the simulation helped them give more directed and in-depth feedback to their peers.

\section{Connecting with the future}

In debriefing, students were able to discuss and identify better ways to approach the clinical situation presented during the simulation. Having a formal debriefing immediately following simulation allowed students to collaboratively discuss different strategies of patient care, enabling them to connect the scenario to their future nursing practice.

Once an error was made in simulation, students connected that error to potential errors that could be made in nursing practice, and felt the lesson learned in simulation would help prevent them from making that error with a real patient. As one student stated "make your mistakes in sim because you'll learn from them so you don't make them out in the real world".

\section{Fidelity}

Simulation fidelity was a recurring theme in students' descriptions of their simulation experiences. Fidelity is the believability or realism of a simulation scenario and includes the physical, psychological, and social aspects of simulation (Meakim et al., 2013). Students commented on the fidelity or realism of the manikin and actors, the scenario itself, equipment and supplies, and their interactions with faculty filling roles in the scenario. Low levels of fidelity were experienced as frustrating or as impeding the students' ability to perform at the levels they desired. High levels of fidelity in the scenario, even when accompanied by low-fidelity elements, were seen as adding to the realism of the simulation experience.

Students identified the manikin used for many of their simulation scenarios as lacking fidelity and thereby influencing their experience of simulation. One way low levels of manikin fidelity had an impact on students was their inability to gather accurate clinical information. For example, students recognized the manikin's lung, heart, and bowel sounds were mechanical in nature. This frustrated them, rendering them incapable of discerning details about the clinical situation. Low levels of manikin fidelity also had other practical implications for implementing clinical interventions. For instance, students were unable to place a nasal cannula on the patient because the manikin does not have ears that allow a nasal cannula to stay in place.

In terms of communication, students described the manikin's facial presentation as unrealistic. This caused some students to feel uncomfortable. The manikin's inability to vary its facial expression was a barrier to the interaction and real-time feedback that students typically relied on to guide their therapeutic communication. Discussing this aspect of the simulation experience, one student wondered, "Are they understanding what I'm saying? Do they look frightened? ...are we having a good relationship? Are they understanding what I'm trying to say? Is it coming across well?” Students 
experienced characteristics of the manikin's voice that did not match the voice characteristics anticipated - for example, a patient intended to be an older male, but whose voice would more typically be associated with a younger female. Students also experienced times when the manikin's voice response was delayed, leading them to wonder whether the delay was a feature of the scenario or indicative of a change in the patient's condition.

High-fidelity confederates, played by human actors, resolved some of the fidelity issues around using mankins. Students felt these confederates were a natural source of cueing and added more realism to the scenario. One student stated: "[Confederates]...could sometimes cue you in a more natural way [by saying], 'She is really pale, she doesn't look like this normally"'. Students expressed this type of cueing from patients' family members was realistic and aligned with what they often experienced during clinical. On the other hand, students expressed discomfort when there was lack of clarity regarding the role the confederate was playing, especially when one confederate had several roles in a single scenario. One student said, "...sometimes the same person walks in with a lab coat and then walks in with a hat, and you're supposed to [recognize] they are [now in] a different [role]."

One group of students mentioned that using "time outs" (a student-initiated pause in the scenario which would allow students to ask for help) drew them out of character and disrupted the flow of the simulation. Students felt it would be more realistic to be able to access resources, such as calling a nurse, rather than calling a "time out".

Sometimes an unrealistic environment made it harder for students to know how to situate themselves in the scenario:

If I were in a realistic hospital room, I walk in and of course I'd wash my hands and put my gloves on....but since this isn't real to me, I feel it's really fake. Maybe it's like I gotta fix it in my head that I just need to pretend or not.

Students also experienced uncertainty about how to engage with confederates in the scenario when the visual cues they were accustomed to having in the clinical setting were not present. For example, on the unit, it would be obvious which person is the charge nurse and which is the certified nurse assistant.

\section{Learning}

Transference of learning improved across clinical and simulation as students progressed through their nursing program. Through simulation, students increased their knowledge and mastered skills by learning from others; learning through reflection; learning through gaining confidence; and learning through gaining experience.

\section{Learning from others}

Students experienced learning while watching streaming video of their colleagues in simulation. They were able to observe how others managed the scenario and tried to reason out rationale for the actions being taken. In addition, learning continued during debriefing while discussing possible approaches to the scenario and listening to others' perspectives. Learning by observing others' physical participation in simulation was perceived to be nearly as beneficial as physically participating in the simulation.

\section{Reflecting}

Reflecting on simulation, either alone or with classmates, facilitated the students' learning.

One student described their personal reflection on simulation, saying:

I replayed parts of it in my head...'I should have done that'...I think it really helped to reflect on what I'd done and what I would have done different and even if I didn't write it out or talk it out with anyone, it still happened in my head internally, like randomly when I was driving, and then I noticed the same thing happened after clinical as well, so it helped me learn a lot from my experience, regardless of whether there was a specific learning activity required afterwards.

Students also described reflecting on simulation in informal settings, even for days and weeks afterwards. For example, some students talked out the simulation experience during the drive home with classmates. For others, reflections on simulation arose during informal, social gatherings. During these gatherings, students discussed what they had done in simulation, what they might have done differently, and otherwise generally debriefed about the simulation.

Some students were given the Lasater rubric instructed to use the rubric guide their reflection. These students experienced a more encapsulated reflective process. One student said, "[When using the rubric], I would go home and write it all out...[and say], 'I learned from that, move on'. And I think without that tool, I was in my head about [the simulation experience] a lot longer."

Students often described errors in simulation as leading to effective learning experiences, saying, “...if you do 
make a mistake, then that's how you learn.” Reflecting on the error during debriefing, including alternate ways of preventing or handling the error, was seen as a valuable learning experience.

\section{Gaining confidence}

Students reflecting back on several years of simulation experiences identified fundamental purposes of simulation. These included developing confidence and communication skills, maintaining situational awareness during intense or unfamiliar situations, and responding calmly. One student described this as "keeping your head ...on your shoulders while you're doing what you're doing".

As students gained more clinical experience and familiarity with particular psychomotor and assessment skills, they became more self-assured and simulation became a better experience for them. Students felt experiences in simulation lead to more learning than repeated practice in the skills lab. Experience in simulation helped students feel more confident going into a patient room once they had an opportunity to start their clinical rotations. Transference of learning across clinical and simulation occurred as students gained more experience in their nursing program.

\section{Gaining experience}

Simulation itself is a skill that can be improved through practice. As students progressed through the program, they were more comfortable with the ambiguity of not knowing what was going to happen during the scenario. Therefore, they were able to embrace simulation as a safe place to make mistakes and learn from them.

With experience, students also stated preparing for simulation became easier. Instead of focusing on individual clinical tasks, students relied on teamwork and the strengths of their team members to assume complementary roles during the simulation:

But you kind of knew each other's strengths and weaknesses, which is real life [because] you work as a team and you know who's good at certain things...and so if you know who you're paired up with, then you know...where to go from [there].

One student expressed openness to approaching simulation as a learning experience, regardless of actual performance or judgments made by those watching the simulation:

...the first few terms of [simulation], what I learned was courage and confidence because...[simulation] was more terrifying, more people were watching, you had less experience doing it, and there was a certain amount of coming up with your plan of what you're going to do, committing to it, and just knowing it might not be right, but if you just give it your all and go for it, your team will help you learn.

\section{Conceptual model}

The Simulation Learning Model - Student Experience (SLM-SE) is a conceptual model which visually represents the result of our findings (See Figure 1). The SLM is read from the bottom to the top. In the SLM-SE, simulation is a teaching and learning approach within which the elements of emotional processing, anxiety and fear, making connections, and fidelity interact with the ultimate goal of learning. Anxiety and fear are barriers to learning. As students used emotional processing to overcome these barriers, it became more possible for them to learn from simulation. In addition, making connections and fidelity appeared to significantly enhance learning.

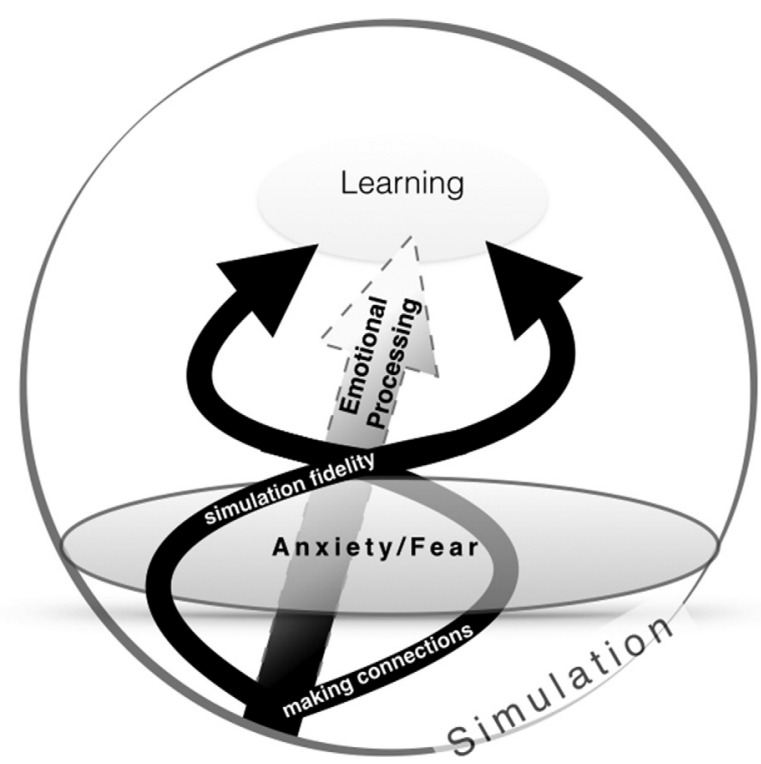

Figure 1: The simulation learning model - student experience (SLM - SE).

\section{Discussion}

While there is a growing body of simulation-related research, this grounded theory study is the first of its kind to explain and conceptualize a holistic approach to understanding the student experience before, during and 
after participation in simulation. A conceptual model of the simulation experience was constructed through qualitative data analysis and included member checking to ensure the accuracy of the study findings and the SLM-SE (see Figure 1). This model explicates the multi-dimensional experience of student learning through high-fidelity simulation.

Our findings suggest that students participating in simulation-based activities found it difficult to cognitively process the events of the simulation until emotional processing had begun. Students varied on their responses noting that processing could begin rather quickly or, in some cases, it may take weeks to fully process through the scenario. Faculty-led supportive, structured debriefing sessions immediately following each simulation case can help facilitate emotional processing, cognitive processing and subsequent learning. Allowing students to view recorded video of their individual simulation performance after debriefing may also facilitate reflection-on-action and subsequent emotional and cognitive processing over time.

Anxiety was identified as a universal experience of students participating in simulation and can either support or hinder learning. High anxiety can be so overwhelming that it inhibits cognitive processing. On the other hand, a low to moderate level of anxiety can lead to new learning. Nielsen and Harder (2013) group patterns of student anxiety into three categories including learning style, simulation-specific concerns and being observed by others. In our study, students discussed feelings of being watched, perceived performance expectations, familiarity with the simulation environment, and comfort with their peer group as influencing their anxiety. As students became a more cohesive group and gained more simulation and clinical experience, they were able to use their experience and engage their peer group to better prepare for and process through simulation activities.

Cordeau (2012) described students' anxiety throughout the simulation process, from pre-simulation through debriefing. Students in our study offered similar descriptions of their anxiety. New insights from this study include how students began to process their anxiety after simulation, and how their experience of anxiety in simulation evolved as they progressed through the program. As student cohorts became more cohesive and gained more simulation and clinical experience, they were able to use their experience and engage their peer group to better prepare for and process through simulation activities.

Fidelity and making connections were identified as strongly influencing anxiety and emotional processing.
High levels of overall simulation fidelity allowed students to make stronger links between the simulation scenario and clinical practice. This finding validates Cordeau's (2012) observation that higher fidelity helped novice students make connections between the simulation and actual patient care, thus reducing anxiety. Students with more clinical experience more readily made such connections without as much reliance on scenario fidelity (Cordeau, 2012). Similarly, making connections to prior experiences, colleagues, and future nursing practice allowed students to better process through the events of the simulation scenario and facilitated the emergence of learning. These findings contribute to the understanding of simulation as a highly social process. Dieckmann, Gaba, and Rall (2007) identified the social aspects surrounding simulation including the: (a) motivation and goals of the simulation instructors and participants; (b) the nature of the simulation encounter, including structure and content; (c) the type of feedback or debriefing provided; and (d) the culture of the organization, including the style of interactions between and among participants and instructors. As the social process of simulation evolves within student cohorts over time, our data suggests that students are better equipped to learn through increasing confidence and experience, continued reflection-on action and enhanced peer-to-peer interaction.

There are several limitations to this study. The first is that the interviews were conducted at only one site and additional investigation would be needed to determine the degree of confirmability. The second limitation is that the investigators were faculty members of the program in which the students were enrolled. The last limitation is that the simulation program evolved over these students course of study; therefore, some differences in the students' experiences maybe related to changes in the simulation program itself.

\section{Future research}

This study was conducted with undergraduate nursing students in a competency-based curriculum. Replicating this study with undergraduate and graduate students in other types of nursing programs is needed to confirm and add to the knowledge of student experience with highfidelity simulation. In addition, more research is needed to better understand the connection between students' experiences and learning. For example, what is the relationship between emotional processing, anxiety, and learning in high-fidelity simulation? Finally, future 
studies could focus on strategies to optimize students' experiences that foster learning in simulation.

Funding: Sigma Theta Tau International Beta Psi Chapter.

\section{References}

Aqel, A. A., \& Ahmad, M. M. (2014). High-fidelity simulation effects on CPR knowledge, skills, acquisition, and retention in nursing students: HFS and CPR knowledge and skills. Worldviews on Evidence-Based Nursing, 11(6): 394-400. doi:10.1111/ wvn.12063

Benner, P., Sutphen, M., Leonard, V., Day, L., \& Schulman, L. (2009). Educating nurses: A call for radical transformation, 1st ed. San Francisco, CA: Jossey-Bass.

Bourdieu, P. (1990). The logic of practice. Stanford, CA: Stanford University Press.

Burns, N., \& Grove, S. (2009). The practice of nursing research: Appraisal, synthesis, and generation of evidence, 6 th ed. St. Louis, MO: Saunders/Elsevier.

Cant, R. P., \& Cooper, S. J. (2010). Simulation-based learning in nurse education: Systematic review: Simulation in nursing. Journal of Advanced Nursing, 66(1): 3-15. doi:10.1111/j.13652648.2009.05240.x

Cordeau, M. A. (2012). Linking the transition: A substantive theory of high-stakes clinical simulation. Advances in Nursing Science, 35(3): E90-E102. doi:10.1097/ANS.0b013e318262614f

Creswell, J. W. (2007). Qualitative inquiry \& research design: Choosing among five approaches, 2nd ed. Thousand Oaks, CA: Sage.

Denzin, N. K. (1978). Sociological methods: A source book, 2nd ed. New York, NY: McGraw-Hill.

Dieckmann, P., Gaba, D., \& Rall, M. (2007). Deepening the theoretical foundations of patient simulation as social practice. Simulation in Healthcare: The Journal of the Society for Simulation in Healthcare, 2(3): 183-193. doi:10.1097/ SIH.0b013e3180f637f5

Draucker, C. B., Martsolf, D. S., Ross, R., \& Rusk, T. B. (2007). Theoretical sampling and category development in grounded theory. Qualitative Health Research, 17(8): 1137-1148. doi: $10.1177 / 1049732307308450$

Dunn, K. E., Osborne, C., \& Link, H. J. (2014). High-fidelity simulation and nursing student self-efficacy: Does training help the little engines know they can? Nursing Education Perspectives, 35(6): 403-404. doi:10.5480/12-1041.1

Glaser, B. G., \& Strauss, A. (1967). The discovery of grounded theory: Strategies for qualitative research. Chicago, IL: Aldine Publishing.

Hayden, J., Smiley, R., Alexander, M., Kardong-Edgren, S., \& Jeffries, P. (2014). Supplement: The NCSBN national simulation study: A longitudinal, randomized, controlled study replacing clinical hours with simulation in prelicensure nursing education. Journal of Nursing Regulation, 5(2): C1-S64.

Institute of Medicine. (2011). The future of nursing: Leading change, advancing health. Consensus Report Washington, DC: National Academies Press.

Jeffries, P. R. (2005). A FRAMEWORK for Designing, Implementing, and Evaluating Simulations Used as Teaching Strategies in Nursing. Nursing Education Perspectives, 26(2): 96-103.

Jensen, R. (2013). Clinical reasoning during simulation: Comparison of student and faculty ratings. Nurse Education in Practice, 13(1): 23-28. doi:10.1016/j.nepr.2012.07.001

Jones, A. L., Reese, C. E., \& Shelton, D. P. (2014). NLN/Jeffries simulation framework state of the science project: The teacher construct. Clinical Simulation in Nursing, 10(7): 353-362. doi:10.1016/j.ecns.2013.10.008

Lasater, K. (2007). Clinical judgment development: Using simulation to create an assessment rubric. The Journal of Nursing Education, 46(11): 496-503.

Lincoln, Y. S., \& Guba, E. G. (1985). Naturalistic Inquiry. Newbury Park, CA: Sage.

McCormick, M. J., de Slavy, J. R., \& Fuller, B. (2013). Embracing technology: Using an unfolding case simulation to enhance nursing students' learning about Parkinson disease. Journal of Neuroscience Nursing, 45(1): 14-20. doi:10.1097/ JNN.0b013e318275b220

Meakim, C., Boese, T., Decker, S., Franklin, A. E., Gloe, D., Lioce, L., \& Borum, J. C. (2013). Standards of best practice: Simulation standard I: terminology. Clinical Simulation in Nursing, 9(6): S3-S11. doi:10.1016/j.ecns.2013.04.001

Miles, M. B., \& Huberman, A. M. (1994). Qualitative data analysis, 2nd ed. Thousand Oaks, CA: Sage.

Nielsen, B., \& Harder, N. (2013). Causes of student anxiety during simulation: What the literature says. Clinical Simulation in Nursing, 9(11): e507-e512. doi:10.1016/j.ecns.2013.03.003

Sandelowski, M. (1993). Rigor or rigor mortis: The problem of rigor in qualitative research revisited. ANS. Advances in Nursing Science, 16(2): 1-8. 